\title{
Effect of dry salting on flavonoid profile and antioxidant capacity of Algerian olive cultivars
}

\author{
O. Souf ${ }^{\mathrm{a}, \bowtie}$, C. Romero ${ }^{\mathrm{b}}$, M.J. Motilva ${ }^{\mathrm{c}}$, X. Borrás Gaya ${ }^{\mathrm{c}}$ and H. Louaileche ${ }^{\mathrm{a}}$ \\ ${ }^{a}$ Laboratoire de Biochimie Appliquée, Faculté des Sciences de la Nature et de la Vie, Université de Bejaia, 06000 Bejaia, Algérie \\ ${ }^{\mathrm{b}}$ Food Biotechnology Department, Instituto de la Grasa (IG-CSIC), Ctra. de Utrera km1, Campus Universitario \\ Pablo de Olavide, Edificio 46, 41013 Sevilla, Spain \\ ${ }^{\mathrm{c}}$ Department of Food Technology CeRTA-TPV, Escuela Técnica Superior de Ingeniería Agraria, Universidad de Lleida, Spain \\ ${ }^{凶}$ Corresponding author: souficqa@yahoo.fr
}

Submitted: 24 June 2015; Accepted: 30 November 2015

SUMMARY: This study investigated the changes in the flavonoid profile and antioxidant capacity of five olive cultivars after dry salting. The antioxidant activity was determined using ferric reducing ability power (FRAP), oxygen radical absorbance capacity (ORAC), and $\beta$-carotene bleaching assays. The results showed that the effects of dry salting on the analyzed parameters were significant $(P<0.05)$. It caused a decrease in total flavonoids with a loss rate of $55 \%$. The HPLC analysis of extracts revealed the presence of four flavonoids: rutin, luteolin-7glucoside, cyanidin-3-glucoside and cyanidin-3-rutinoside. Among the studied cultivars, Azeradj was characterized by high levels of flavonoids. Concerning the antioxidant activity, diverging results were obtained using different antioxidant assays. Overall, the dry salting induced a reduction in the antioxidant activity with variable values depending on the cultivar. Among the used methods, high correlations were found between flavonoid contents and the FRAP assay.

KEYWORDS: Antioxidant activity; Cultivar; Dry salting; Flavonoid; HPLC; Olive

RESUMEN: Efecto de la salazón en seco sobre el perfil de flavonoides y la capacidad antioxidante de cultivares Argelinos. En este estudio se investigó los cambios en el perfil de flavonoides y la capacidad antioxidante de cinco cultivares de olivo después de una salazón en seco. La actividad antioxidante se determinó mediante los métodos FRAP (Ferric ion Reducing Antioxidant Power), ORAC (capacidad de absorción de radicales de oxígeno) y ensayos de blanqueo de $\beta$-caroteno. Los resultados mostraron que los efectos de la salazón en seco en los parámetros analizados fueron significativos $(P<0,05)$. Esto causó una disminución en los flavonoides totales con una tasa de pérdida del 55\%. El análisis por HPLC de los extractos reveló la presencia de cuatro flavonoides: rutina, luteolina-7-glucósido, cianidina-3-glucósido y cianidina-3-rutinósido. Entre los cultivares estudiados, Azeradj se caracteriza por altos niveles de flavonoides. En cuanto a la actividad antioxidante, se obtuvieron resultados divergentes utilizando diferentes ensayos antioxidantes. En general, la salazón en seco indujo una reducción en la actividad.

PALABRAS CLAVE: Aceituna; Actividad antioxidante; Cultivares; Flavonoides; HPLC; Salazón

Citation/Cómo citar este artículo: Soufi O, Romero C, Motilva MJ, Borrás Gaya X, Louaileche H. 2016. Effect of dry salting on flavonoid profile and antioxidant capacity of Algerian olive cultivars. Grasas Aceites 67 (2): e132. doi: http:// dx.doi.org/10.3989/gya.0641152.

Copyright: (C) 2016 CSIC. This is an open-access article distributed under the terms of the Creative Commons Attribution-Non Commercial (by-nc) Spain 3.0 Licence. 


\section{INTRODUCTION}

The olive tree (Olea europaea) is widely cultivated in many regions of the world where climatic conditions are as favorable as those prevailing in the Mediterranean countries. During the last decade, the evolution of the Algerian market concerning table olives was characterized by a production that has evolved in a fluctuating trend of one olive crop to another. Algeria's olive crop area was around 188,923 ha by 2011 . The total table olive production was estimated to be 192,785 tons in 2011 (ITAFV, 2011). The olives cultivated in Algeria belong to a wide range of cultivars including Azeradj, Bouchouk, Aberkane and Atefah.

In recent years, particular attention has been focused on the specific olive polyphenols which constitute a complex mixture of flavonoid and nonflavonoid compounds. Romero et al. (2002a) identified the olive flavonoids as quercetin-3-O-rutinoside (rutin), luteolin-7-glucoside, quercetin-3-rhamnoside, cyanidin-3-glucoside and cyanidin-3-rutinoside. These substances contribute to the total antioxidant potential of the diet and thus may lower the risk of cancer and some chronic diseases. The flavonoids inhibit lipid peroxidation and exhibit various physiological activities, including antiinflammatory, anti-allergic, anti-carcinogenic, antihypertensive and anti-arthritic activities (Erlund, 2004). Recently, Dhanya et al. (2014) demonstrated that quercetin and the aglycone of rutin are considered as dietary supplements with potential for the prevention and treatment of type 2 diabetes and to suppress oxidative stress-mediated damage in diabetic pathophysiology.

In a previous investigation, we have demonstrated that elaboration with dry salt significantly affects the ortho-diphenol profile of six black olive cultivars and the antioxidant capacity of the final product (Soufi et al., 2014). In the current study, we aim to analyze another class of phenolics which are the flavonoids of five Algerian olive cultivars, in order to obtain a more accurate estimation of olive polyphenols. Total flavonoid contents were also determined to establish a relationship between these classes of compounds and the antioxidant activity of both fresh and salted olives. As far as we know, this report is the first to focus on the flavonoid composition of Algerian olive cultivars, particularly after dry salting.

Since olive polyphenols have multiple characteristics, no single assay available provides all of the information desired. For this reason, the evaluation of overall antioxidant capacity may require multiple assays. Hence, this work aims also to use three methods (FRAP, ORAC and $\beta$-carotene bleaching) based on different mechanisms to estimate the antioxidant capacity of both fresh and salted olives.

\section{MATERIALS AND METHODS}

\subsection{Olive samples}

Five black olive cultivars (Azeradj, Bouchouk, Abelout, Aberkane and Atefah) harvested at the fully ripe stage were hand-picked from different parts of olive trees in the Bejaia location (north of Algeria), in December, 2010.

\subsection{Processing of olive samples}

The collected olives (at least $2 \mathrm{Kg}$ ) were treated with alternating layers of dry salt $(0.8 \mathrm{Kg})$, in baskets, and kept at room temperature for 30 to 50 days depending on the cultivar (Panagou, 2006). The salting caused dehydration and the olives appeared shriveled. The fresh and salted olive pulps were freeze-dried (Christ, Alpha 1-4 LDplus, Osterode am Harz, Germany), then ground in an electric blender (IKA model A 11 B, Staufen, Germany) and stored at $-18^{\circ} \mathrm{C}$ until analysis.

\subsection{Extract preparation}

Freeze dried olive pulp $(100 \mathrm{mg})$ was homogenized with $10 \mathrm{~mL}$ of $50 \%$ acetone. After stirring for $30 \mathrm{~min}$, the mixture was centrifuged (nüve NF 200, Ankara, Turkey) at 2800x $g$ for $20 \mathrm{~min}$. The supernatant was collected and filtered, and the residue was re-extracted. The filtered extracts were combined, washed with hexane $(5 \times 10 \mathrm{~mL})$, and then kept in the refrigerator until analysis (McDonald et al., 2001).

\subsection{Flavonoid analysis}

\subsubsection{Total flavonoids}

Total flavonoid contents were determined according to the procedure of Kim et al. (2003). An aliquot of sample $(200 \mu \mathrm{L})$ was mixed with distillated water $(800 \mu \mathrm{L})$. A volume of $60 \mu \mathrm{L}$ of $5 \% \mathrm{NaNO}_{2}$ was added to the flask. After $5 \mathrm{~min}, 60 \mu \mathrm{L}$ of $10 \% \mathrm{AlCl}_{3}$ were added. At 6 min, $40 \mu \mathrm{L}$ of $\mathrm{NaOH}(1 \mathrm{M})$ were added to the mixture. Immediately, the contents of the reaction flask were diluted with the addition of $480 \mu \mathrm{L}$ of water and thoroughly mixed. Absorbance of the mixture was measured at $510 \mathrm{~nm}$. Catechin was used as standard and the amount of flavonoids was calculated as milligrams of catechin equivalents (CE) per $100 \mathrm{~g}$ of dry weight.

\subsubsection{Individual flavonoids}

\subsubsection{Non-anthocyanin compounds}

The preparation of extracts was based on the methodology proposed by Sánchez et al. (2013). Freeze dried olive pulp (1 g) was homogenized with $6 \mathrm{~mL}$ of dimethylsulfoxide (DMSO). 
After stirring for $2 \mathrm{~min}$, the mixture was centrifuged at $28000 \times g$ for $6 \mathrm{~min}$ at $22^{\circ} \mathrm{C}$; the supernatant was collected and filtered through a $0.22 \mu \mathrm{m}$ nylon filter. An aliquot of filtrate $(250 \mu \mathrm{L})$ was diluted with 500 $\mu \mathrm{L}$ of DMSO and $250 \mu \mathrm{L}$ of $0.2 \mathrm{mM}$ syringic acid (internal standard). A volume of this mixture (20 $\mu \mathrm{L}$ ) was injected for HPLC analysis; a flow rate of $1 \mathrm{~mL} \cdot \mathrm{min}^{-1}$ and a temperature of $35^{\circ} \mathrm{C}$ were used.

The HPLC system consisted of a Waters 717 plus autosampler, a Waters 600 E pump, a Waters column heater module, and a Waters 996 photodiode array detector operated with Empower software (Waters Inc). A $25 \mathrm{~cm} \times 4.6 \mathrm{~mm}$ i.d., $5 \mu \mathrm{m}$, Spherisorb ODS-2 (Waters Inc.) column was used. The separation was achieved by gradient elution using an initial composition of $90 \%$ water $(\mathrm{pH} 2.5$ adjusted with $0.15 \%$ phosphoric acid) and 10\% methanol. The concentration of the latter solvent was increased to $30 \%$ in $10 \mathrm{~min}$ and maintained for $20 \mathrm{~min}$. Subsequently, the methanol percentage was raised to $40 \%$ in $10 \mathrm{~min}$, which was maintained for $5 \mathrm{~min}$. Finally, the methanol concentration for the last three steps was increased to 60,70 , and $100 \%$ in 5 min periods. Initial conditions were reached in $15 \mathrm{~min}$. Chromatograms were recorded at $280 \mathrm{~nm}$ (Romero et al., 2002b). The concentration of each compound was calculated using a standard curve. Luteolin 7-O-glucoside and rutin were purchased from Extrasynthese SA (Lyon Nord, Genay, France).

\subsubsection{Anthocyanin compounds}

Extraction was based on the methodology proposed by Romero et al. (2002a). Anthocyanins were extracted from $4 \mathrm{~g}$ of freeze-dried olive pulp using $6 \times 30 \mathrm{~mL}$ of methanol:hydrochloric acid (99:1, V/V) at $0{ }^{\circ} \mathrm{C}$. The mixture was stirred for $1 \mathrm{~min}$ then centrifuged at $9000 \mathrm{~g}$ during $6 \mathrm{~min}\left(10^{\circ} \mathrm{C}\right)$. A volume of $20 \mathrm{~mL}$ of a solution (water:hydrochloric acid 99/1, V/V) was added to the methanolic extract which was then concentrated under vacuum at $30^{\circ} \mathrm{C}$ until water residue then transferred to a $25 \mathrm{~mL}$ flask with acidified water. A washing step with $4 \times 50 \mathrm{~mL}$ of hexane was carried out to remove the fat from the extract. Finally, the extract was filtered through a $0.22 \mu \mathrm{m}$ filter and injected into HPLC.

The HPLC system consisted of a Waters 2695 Alliance with a pump, column heater, and autosampler modules included-Detection was carried out with a Waters 996 photodiode array detector. The system was controlled with Millennium software (Waters Inc., Milford, MA) A $25 \mathrm{~cm} \times 4.6 \mathrm{~mm}$ i.d., 5- $\mu \mathrm{m}$ Extrasil ODS-2 (Technokroma, Barcelona, Spain) column was used and the elution conditions were as follows: flow rate $=1 \mathrm{~mL} \cdot \mathrm{min}^{-1}$; column temperature $40{ }^{\circ} \mathrm{C}$, sample temperature $10^{\circ} \mathrm{C}$, solvent $\mathrm{A}$, water with $1 \%$ perchloric acid, solvent $\mathrm{B}$, methanol. The mobile phase consisted initially of $80 \%$ of $\mathrm{A}$; using a linear gradient, the concentration of methanol was increased to $50 \%$ over $35 \mathrm{~min}$, to $98 \%$ at $40 \mathrm{~min}$, held for $2 \mathrm{~min}$ at $98 \%$ of $\mathrm{B}$ to wash the column, and then returned to the initial conditions $(20 \%$ of B) for $10 \mathrm{~min}$. Chromatograms were recorded at $520 \mathrm{~nm}$. The evaluation of each anthocyanin compound was performed using a four-point regression curve obtained using the available standards; cyanindin-3-O-glucoside and cyanidin-3-Orutinoside were purchased from Extrasynthese S.A. (Lyon Nord, Genay, France).

\subsection{Antioxidant activity}

\subsubsection{FRAP assay}

The ferric reducing antioxidant power (FRAP) was applied as described by Benzie and Strain (1996). A volume of acetate buffer $(160 \mu \mathrm{L})$ was added to $20 \mu \mathrm{L}$ of sample. The mixture was placed in a well plate and put in the spectrophotometer (Thermo Scientific, Madrid, Spain) at $37^{\circ} \mathrm{C}$, then mixed during $2 \mathrm{~min}$. After that, $40 \mu \mathrm{L}$ of $\mathrm{FeCl}_{3}$ $(10 \mathrm{mM})$ and $40 \mu \mathrm{L}$ of 2,4,6-tripyridyl-s-triazine TPTZ (33\%) were added, and the absorbance was recorded at $593 \mathrm{~nm}$ after $10 \mathrm{~min}$. The results were calculated and related to a $\mathrm{Fe}^{+2}$ standard solution tested in parallel and expressed in micromol of $\mathrm{FeSO}_{4}$ per gram of dry weight $(\mu \mathrm{mol}$ of $\left.\mathrm{Fe}^{+2} \cdot \mathrm{g}^{-1} \mathrm{dw}\right)$.

\subsubsection{Hydrophilic ORAC}

The hydrophilic oxygen radical absorbance capacity (ORAC) assay is limited to the measurement of the hydrophilic chain breaking against peroxyl radicals. A further dilution of the olive extract was made with phosphate buffer. A portion of $25 \mu \mathrm{L}$ of the diluted sample was added to a well in a 48 -well microplate. A volume of $180 \mu \mathrm{L}$ of fluorescein solution $\left(0.45 \mathrm{mg} \cdot \mathrm{mL}^{-1}\right)$ and $75 \mu \mathrm{L}$ of the 2,2'-azobis (2-amidino-propane) dihydrochloride AAPH $\left(60 \mathrm{mg} \cdot \mathrm{mL}^{-1}\right)$ were added to the assay mixture. ORAC values were calculated and expressed as micromol of trolox equivalents per gram of dry weight $\left(\mu \mathrm{mol}\right.$ of $\mathrm{TE} \cdot \mathrm{g}^{-1} \mathrm{dw}$ ) (Prior et al., 2003).

\subsection{3. $\beta$-Carotene bleaching assay}

Antioxidant activity was estimated according to the procedure described by Velioglu et al. (1998). A $\beta$-carotene solution was prepared in chloroform $\left(0.12 \mathrm{mg} \cdot \mathrm{mL}^{-1}\right)$. Next, $3 \mathrm{~mL}$ were taken and added to a flask containing $40 \mathrm{mg}$ of linoleic acid in 400 $\mathrm{mg}$ of tween 20. The chloroform was removed in a vacuum evaporator, and then $100 \mathrm{~mL}$ of hydrogen peroxide $(30 \%)$ were added. After thorough mixing, $3 \mathrm{~mL}$ of the emulsion were added to $0.5 \mathrm{~mL}$ of extract (without washing with hexane). 
The oxidation of $\beta$-carotene emulsion was monitored at $470 \mathrm{~nm}$ after incubation at $50{ }^{\circ} \mathrm{C}(120 \mathrm{~min})$. The antioxidant activity was expressed as percent inhibition relative to the control using the following equation:

$\mathrm{AA}=\left(\mathrm{R}_{\text {control }}-\mathrm{R}_{\text {sample }}\right) \times 100 / \mathrm{R}_{\text {control }}$

Where $R_{\text {control }}$ and $R_{\text {sample }}$ were the bleaching rates of $\beta$-carotene in the reactant mixture without antioxidants and with olive extracts, respectively.

\subsection{Statistical analysis}

Results were expressed as means \pm standard deviation (SD). The statistical analysis of the data was carried out with STATISTICA 5.5 Fr. Analysis of variance (ANOVA) was performed to estimate the statistically significant differences among the olive samples for each parameter. $P$ values $<0.05$ were regarded as significant.

\section{RESULTS AND DISCUSSION}

\subsection{Flavonoid analysis}

\subsubsection{Total flavonoids}

The results showed significant differences $(P<0.05)$ in the total flavonoid contents among the studied cultivars (Table 1). The total flavonoid concentration of cultivars ranged between a mean value of 872 (Aberkane and Abelout) and $1537 \mathrm{mg}$ $\mathrm{CE} \cdot 100 \mathrm{~g}^{-1} \mathrm{dw}$ (Azeradj) in fresh olives. These contents are higher than those obtained by Brahmi et al. (2013) who used methanol as the extraction solvent. However, the flavonoid amounts are comprised only between 394 (Abelout) and $1272 \mathrm{mg} \mathrm{CE} \cdot 100 \mathrm{~g}^{-1} \mathrm{dw}$ (Azeradj) in salted olives. Consequently, the dry salting caused a decrease in flavonoid contents with a
TABLE 1. Total flavonoid contents of the studied olives

\begin{tabular}{lccc}
\hline & & \multicolumn{2}{c}{ Total flavonoids $^{\mathbf{1}}$} \\
\cline { 3 - 4 } Cultivar & Code & Fresh olives & salted olives \\
\hline Azeradj & AZ & $1537 \pm 68^{\mathrm{aA}}$ & $1272 \pm 82^{\mathrm{aB}}$ \\
Abelout & $\mathrm{BT}$ & $844 \pm 20^{\mathrm{dA}}$ & $394 \pm 17^{\mathrm{dB}}$ \\
Aberkane & $\mathrm{BK}$ & $902 \pm 8^{\mathrm{dA}}$ & $608 \pm 38^{\mathrm{bB}}$ \\
Atefah & $\mathrm{T}$ & $1038 \pm 44^{\mathrm{cA}}$ & $593 \pm 27^{\mathrm{bcB}}$ \\
Bouchouk & $\mathrm{B}$ & $1149 \pm 28^{\mathrm{Ba}}$ & $493 \pm 23^{\mathrm{cdB}}$ \\
\hline
\end{tabular}

$\mathrm{A}$ and $\mathrm{B}$ : within the same row (effect of processing), different letters indicate statistically significant differences $(p<0.05)$.

a-d: Within the same column, different letters indicate statistically significant differences $(p<0.05)$ among cultivars.

${ }^{1}$ Results in mg CE$\cdot 100 \mathrm{~g}^{-1} \mathrm{dw}$ are expressed as the average \pm Standard deviation of three replicates.

loss rate ranging from $22 \%$ (Azeradj) to a mean value of 55\% (Abelout and Bouchouk). This decrease can be explained by the diffusion of these compounds under the action of salt and/or their oxidation during salting. Furthermore, the variability of the decrease noted among the studied cultivars can be related to the characteristics of each cultivar such as diameter of fruit, since the decrease is related to the diffusion of such compounds (Bianchi, 2003). In addition, the difference of the polarity of each flavonoid compound can also influence their diffusion (Tomás-Barberán and Gil, 2008).

\subsubsection{Individual flavonoids}

The analysis of the studied cultivars showed considerable quantitative differences $(P<0.05)$ in individual flavonoids (Table 2). Four flavonoids were identified: rutin, luteolin-7- $O$-glucoside, cyanidin-3-O-glucoside and cyanidin-3-O-rutinoside. The presence of rutin and luteolin-7-glucoside in olive fruits was always reported (Brenes et al., 1995; Morello et al., 2005; Savarese et al., 2007) except that the fresh olives in the present study did not contain

TABLE 2. Individual flavonoids ${ }^{1}$ of fresh and salted olives evaluated by HPLC-DAD

\begin{tabular}{|c|c|c|c|c|c|}
\hline $\begin{array}{l}\text { Flavonoid compound } \\
\text { Fresh olives }\end{array}$ & Azeradj & Abelout & Aberkane & Atefah & Bouchouk \\
\hline Luteolin-7-Glucoside & nd & nd & nd & nd & nd \\
\hline Quercetin-3-rutinoside (rutin) & $1857.16 \pm 79.72^{\mathrm{aA}}$ & $227.63 \pm 22.41^{\mathrm{cA}}$ & $410.73 \pm 0.41^{\mathrm{bA}}$ & $461.94 \pm 61.96^{\mathrm{bA}}$ & $454.27 \pm 61.52^{\mathrm{bA}}$ \\
\hline Cyanidin-3-glucoside & $2587.98 \pm 48.58^{\mathrm{a}}$ & $527.65 \pm 07.00^{\mathrm{b}}$ & $242.79 \pm 02.65^{\mathrm{c}}$ & $03.50 \pm 00.58^{\mathrm{d}}$ & $28.55 \pm 01.53^{\mathrm{d}}$ \\
\hline Cyanidin-3-rutinoside & $4358.09 \pm 24.38^{\mathrm{aA}}$ & $966.60 \pm 02.70^{\mathrm{bA}}$ & $751.98 \pm 37.89^{\mathrm{cA}}$ & $27.26 \pm 04.05^{\mathrm{eA}}$ & $78.85 \pm 04.41^{\mathrm{dA}}$ \\
\hline \multicolumn{6}{|l|}{ Salted olives } \\
\hline Luteolin-7-glucoside & $370.54 \pm 48.92^{\mathrm{a}}$ & $29.81 \pm 5.94^{\mathrm{d}}$ & $122.96 \pm 08.94^{\mathrm{c}}$ & $300.11 \pm 25.35^{\mathrm{b}}$ & $116.15 \pm 8.33^{\mathrm{c}}$ \\
\hline Quercetin-3-rutinoside (rutin) & $473.89 \pm 59.84^{\mathrm{aB}}$ & $24.76 \pm 04.66^{\mathrm{cB}}$ & $94.87 \pm 10.44^{\mathrm{bB}}$ & $91.51 \pm 00.73^{\mathrm{bB}}$ & $84.26 \pm 04.12^{\mathrm{bB}}$ \\
\hline Cyanidin-3-glucoside & nd & nd & nd & nd & nd \\
\hline Cyanidin-3-rutinoside & $16.70 \pm 04.81^{\mathrm{aB}}$ & $11.50 \pm 02.06^{\mathrm{bB}}$ & $07.16 \pm 01.27^{\mathrm{cB}}$ & nd & nd \\
\hline
\end{tabular}

${ }^{1}$ Results are expressed in $\mathrm{mg} \cdot \mathrm{Kg}^{-1}$ of dried weight \pm standard deviation; for each row, different letters (a-d) indicate statistically significant differences (ANOVA test, $P<0.05$ ) among cultivars; $n$.d.: not detected; A and B: within the same column for each compound (effect of processing). 
the luteolin-7-glucoside until they were treated. Also, Romero et al. (2002a) identified cyanidin-3-Oglucoside and the cyanidin-3-O-rutinoside as the main pigments in seven natural black olive cultivars.

The amount of rutin in fresh olives varied between 227 (Abelout) and $1857 \mathrm{mg} \cdot \mathrm{Kg}^{-1} \mathrm{dw}$ (Azeradj). These contents are similar to those found by Sousa et al. (2014) and Morello et al. (2005) except for the Azeradj cultivar which contain a high concentration. This finding is similar to that reported by Garrido-Fernández et al. (1997) who consider that the flavonoid composition is useful for the biochemical characterization of olive cultivars.

The content of cyanidin-3-glucoside in fresh olives varied from a mean value of 16 (Bouchouk and Atefah) to $2588 \mathrm{mg} \cdot \mathrm{Kg}^{-1} \mathrm{dw}$ (Azeradj), whereas, the concentration of cyanidin-3-rutinoside is comprised between 27 (Atefah) and $4358 \mathrm{mg} \cdot \mathrm{Kg}^{-1} \mathrm{dw}$ (Azeradj). These amounts are relatively higher than those obtained by Romero et al. (2002a). The olive cultivars of the present study had the characteristic that the cyanidin-3-glucoside amount is higher than that of cyanidin-3-rutinoside. This could represent a useful tool for a phytochemical characterization of the cultivars.

After processing, we noted a decrease in individual flavonoid contents except for luteolin-7-glucoside. The content of luteolin-7-glucoside ranged from 30 (Abelout) to $370 \mathrm{mg} \cdot \mathrm{Kg}^{-1} \mathrm{dw}$ (Azeradj). These amounts are higher than the luteolin content reported by Dimitrios (2006) for Greek-style naturally black olives $\left(25-75 \mathrm{mg} \cdot \mathrm{Kg}^{-1} \mathrm{dw}\right)$, although the rutin content ranged between 24 (Abelout) and 474 $\mathrm{mg} \cdot \mathrm{Kg}^{-1} \mathrm{dw}$ (Azeradj). Piscopo et al. (2014) reported a decrease in the quercetin amount after the drying of green olives. Also, Brenes et al. (1995) noted that the rutin content of the olive flesh decreased with the alkaline treatment, and practically disappeared after the washing step. In the adopted method, the content of this compound decreased but it did not disappear. This reduction can be attributed to the glycosidic bond breaking during salting.

The obtained results indicate that the effect of dry salting is dependent on the individual flavonoids; it can induce a decrease (rutin) or an increase (luteolin-7-glucoside). This is in agreement with the data reported by Rice-Evans and Packer (2003), since salt can generate sodium adducts from flavonol-3-glucoside (rutin), and consequently, the content of the latter decreases. By contrast, these adducts are not obtained from flavone glucoside (luteolin-7-glucoside).

The dry salting significantly affects $(P<0.05)$ the content of olive pigments: the cyanidin-3glucoside disappeared, but the cyanidin-3-rutinoside is detected only in three cultivars with concentrations of 7 (Aberkane), 11 (Abelout) and $16 \mathrm{mg} / \mathrm{Kg}$ $\mathrm{dw}$ (Azeradj). This can be explained by the fact that anthocyanins are water-soluble compounds which diffused from the olive to the surrounding medium during dry salting. These substances can also be either transformed or degraded during processing. According to Garrido-Fernández et al. (1997), the anthocyanin contents may be strongly influenced by the processing and the cultivar; the total content can decrease to below $50 \%$ of its initial value.

The cultivar had a significant effect on the observed changes in the flavonoid composition of studied olives. Among the investigated cultivars, for both fresh and salted olives, Azeradj showed the highest flavonoid levels and even higher than that of other studies on olive cultivars (Morello et al., 2005; Damak et al., 2008).

\subsection{Antioxidant activity}

\subsubsection{FRAP assay}

The antioxidant capacity of olive extracts is determined by the ability of the antioxidants to reduce ferric to ferrous iron. The statistical analysis showed significant differences $(P<0.05)$ in the FRAP values of the studied olive cultivars. They varied from 126 (Bouchouk) to $353 \mu \mathrm{mol}$ of $\mathrm{Fe}^{+2} \cdot \mathrm{g}^{-1} \mathrm{dw}$ (Azeradj) for fresh olives, while these activities ranged between 127 (Bouchouk) and $209 \mu \mathrm{mol}$ of $\mathrm{Fe}^{+2} \cdot \mathrm{g}^{-1} \mathrm{dw}$ (Azeradj) for salted ones (Figure.1). These data reveal that both fresh and salted olive extracts showed a marked capacity for iron reduction with values higher than those obtained by Ziogas et al. (2010). The ferric reducing antioxidant power of both fresh and salted olive cultivars decreased in the following order: Azeradj $>$ Abelout $=$ Aberkane $>$ Atefah $>$ Bouchouk. The processing had a significant effect $(P<0.05)$

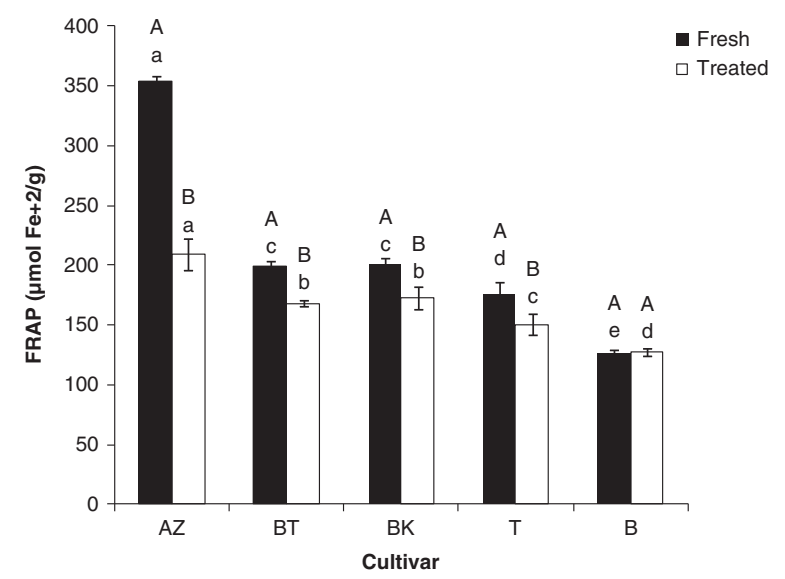

Figure 1. Ferric Reducing Antioxidant Power of olive cultivars. Effect of salting (A-B): different letters indicate statistically significant differences $(P<0.05)$. (a-e) Different letters indicate statistically significant differences $(P<0.05)$ among cultivars. BT, BK, AZ, B, T: are codes corresponding to each cultivar (indicated in Table 1). 
on this activity. Overall, we noted a decrease in ferric reducing capacity except for Bouchouk cultivar, which showed a stable activity. The decrease varied between a mean value of $16 \%$ (Abelout and Aberkane) and $41 \%$ (Azeradj). This result could be explained by the low contents of flavonoids and/ or other reducing agents in salted olives, since, the antioxidant capacity of flavonoids has been attributed to their electron-donating ability (MoralesSoto et al., 2014). Also, Prior et al. (2005), consider that the reducing capacity is related to the degree of hydroxylation which is a characteristic of flavonoid compounds. The present study demonstrated that other factors such as the structure of antioxidant could also influence this activity, since Azeradj cultivar which had the lowest loss rate of flavonoids, lost almost half of its activity, while inverse effect was noted for the Abelout cultivar.

\subsubsection{Hydrophilic ORAC (ORACH)}

Figure 2 shows significant differences in antioxidant activity among the studied cultivars $(P<0.05)$ : $\mathrm{ORAC}_{\mathrm{H}}$ values ranged between 201 (Bouchouk) and $551 \mu \mathrm{mol} \mathrm{TE} \cdot \mathrm{g}^{-1} \mathrm{dw}$ (Azeradj) in fresh olives; these values varied from 199 (Atefah) to $418 \mu \mathrm{mol} \mathrm{TE} \cdot \mathrm{g}^{-}$ ${ }^{1} \mathrm{dw}$ (Aberkane) in salted ones.

The obtained results indicate that dry salting had a significant effect on the antioxidant capacity $(P<0.05)$; it leads to a decrease for the studied cultivars except for Bouchouk which showed an increase of $37 \%$. In fact, the loss rate varied from 13 (Aberkane) to 47\% (Azeradj). The scavenging effects of fresh olive cultivars against the oxygen radical

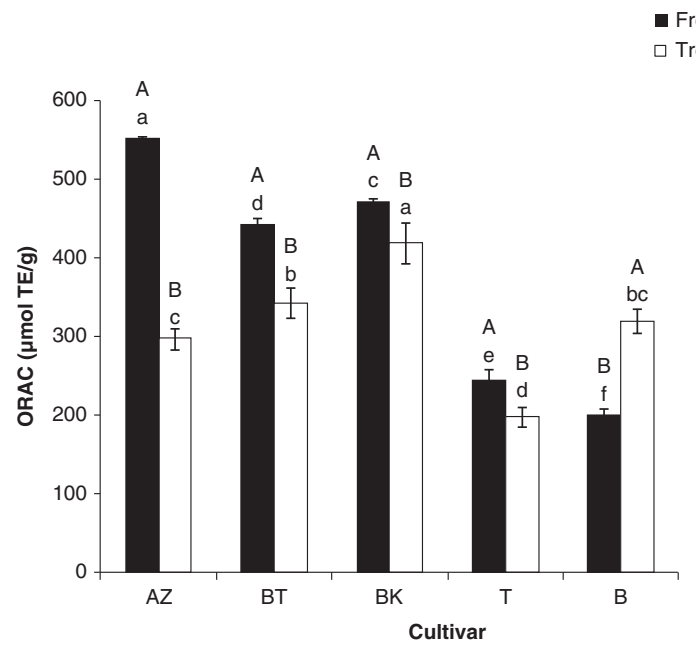

FIgURe 2. Oxygen absorbing Power Capacity of olive cultivars. Effect of salting (A-B): different letters indicate statistically significant differences $(P<0.05)$. (a-e) Different letters indicate statistically significant differences $(P<0.05)$ among cultivars. BT, BK, AZ, B, T: are codes corresponding to each cultivar (indicated in Table 1) decreased in the following order: Azeradj $>$ Aberkane $>$ Abelout $>$ Atefah $>$ Bouchouk. After processing, this order changed to the following: Aberkane $>$ Abelout $\geq$ Bouchouk $>$ Azeradj $>$ Atefah. This variation could be related to the specific changes in phenolic composition of each cultivar after processing, since the ORAC assay cannot be based only on the flavonoids which are effective electron-donors, but also includes the hydrogen donor compounds. On the other hand, the increase noted for Bouchouk cultivar can be explained by the possible synergistic effect between the antioxidant compounds detected after processing.

On the other hand, the results reveal that the cultivar containing high levels of rutin did not show necessarily low $O R A C_{H}$ values. This osbervation is different than that of Ou et al. (2002). This can be related to the specific antioxidant composition of the olive cultivar and the possible synergistic effect of other antioxidants with rutin in the total ORAC assay.

\subsection{3. $\beta$-Carotene bleaching assay}

The antioxidant activity of olive extracts measured by the bleaching of $\beta$-carotene is shown in Figure. 3.The statistical analysis $(P<0.05)$ revealed that the fresh olive extracts showed an inhibition rate which ranged between 32 (Aberkane) and 54\% (Bouchouk).

Concerning the treated olives, the inhibition activity varied from 17 (Atefah) to a mean value of 33\% (Aberkane and Abelout). Dry salting significantly affected the $\beta$-carotene bleaching activity of the studied olives except for the Aberkane cultivar; it induced

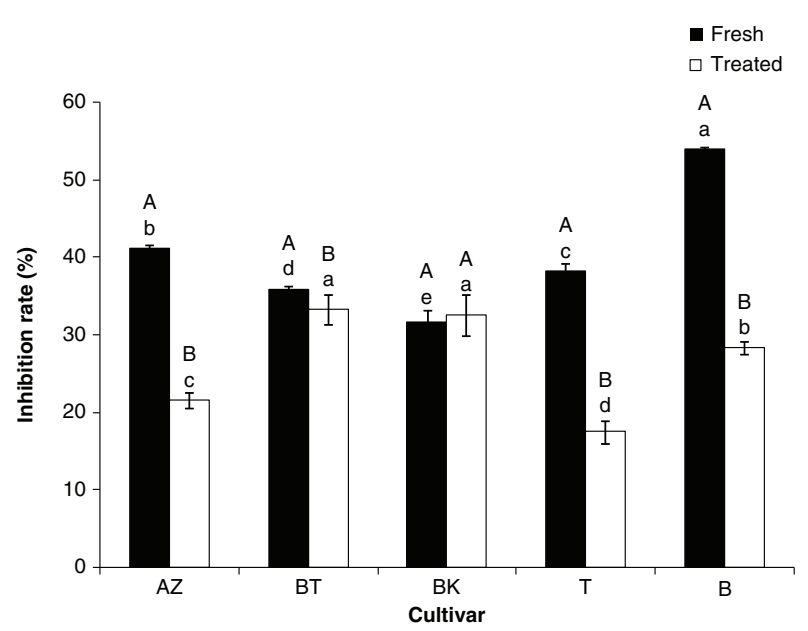

FigURE 3. $\beta$-Carotene bleaching activity of olive cultivars. Effect of salting (A-B): different letters indicate statistically significant differences $(P<0.05)$. (a-e) Different letters indicate statistically significant differences $(P<0.05)$ among cultivars. BT, BK, AZ, B, T: are codes corresponding to each cultivar (indicated in Table 1) 
a loss with a rate comprised between $9 \%$ (Abelout) and $52 \%$ (Atefah). We note that Azeradj cultivar, which showed high values of ORAC and FRAP, had a relatively low inhibition effect of $\beta$-carotene oxidation. This can be related to its low content in lipophilic antioxidants, which may play a major role in this activity since the extracts in the $\beta$-carotene bleaching assay are not defatted and contain both lipophilic and hydrophilic antioxidants. This observation is similar to that of Alu'datt et al. (2013) who demonstrated that full-fat olive extracts had higher antioxidant activity than de-fatted extracts.

Because multiple reaction characteristics and mechanisms are likely involved, each method only provides an estimate of antioxidant capacity which is subjective to its conditions and reagents.

\subsection{Relationship between flavonoid contents and antioxidant activity}

The statistical study showed that the correlation coefficient did not depend only on the applied method, but, also on the olive processing, which significantly affected its composition (Table 3). A good correlation was obtained between total flavonoid contents and FRAP, thus reflecting the role of such compounds as reducers of iron. This observation is in accordance with that of Du et al. (2009).

The present study also demonstrated that the correlation between the total flavonoid contents and ORAC of fresh olives is characterized by higher coefficients than those of salted ones. This can signify that ORAC method is dependent on the flavonoid concentration since a considerable loss in these compounds occured after processing. On the other hand, a low correlation was noted between the analyzed compounds (individual flavonoids and total flavonols) and the $\beta$-carotene bleaching activity. These results are in agreement with those obtained by Rufino et al. (2010) who did not find any correlation between antioxidant compounds and $\beta$-carotene bleaching activity. This can reflect the contribution of other compounds rather than flavonoids to this antioxidant capacity and/or variations in the efficiency of individual olive phenolics or in combination.

The comparison of the antioxidant assays used revealed a good correlation between FRAP and

TABLE 3. Correlation coefficients $(\mathrm{R}) *$ for the relationship between the antioxidant compounds and the antioxidant potential measured by FRAP (Ferric Reducing Ability of Plasma), ORAC

(Oxygen Radical Absorbance Capacity) and $\beta$-carotene bleaching activity (CBA)

\begin{tabular}{lcccc}
\hline & \multicolumn{2}{c}{ Fresh olives } & \multicolumn{2}{c}{ Salted olives } \\
\cline { 2 - 5 } Correlation between & $(\mathbf{R})^{*}$ & Equation & $(\mathbf{R})^{*}$ & Equation \\
\hline Flavonoids- FRAP & 0.70 & $\mathrm{y}=0.216 \mathrm{x}-25.8$ & 0.78 & $\mathrm{y}=0.069 \mathrm{x}+118.8$ \\
Flavonoids- ORAC & 0.24 & $\mathrm{y}=0.134 \mathrm{x}+235.6$ & 0.14 & $\mathrm{y}=-0.034 \mathrm{x}+338.7$ \\
Flavonoids- CBA & 0.43 & $\mathrm{y}=0.013 \mathrm{x}+25.82$ & 0.50 & $\mathrm{y}=-0.01 \mathrm{x}+33.44$ \\
Flavonols- FRAP & 0.94 & $\mathrm{y}=2.026 \mathrm{x}-91.0$ & 0.86 & $\mathrm{y}=0.532 \mathrm{x}+78.0$ \\
Flavonols- ORAC & 0.73 & $\mathrm{y}=2.809 \mathrm{x}-35.8$ & 0.23 & $\mathrm{y}=0.377 \mathrm{x}+253.6$ \\
Flavonols- CBA & 0.11 & $\mathrm{y}=-0.025 \mathrm{x}+43.91$ & 0.03 & $\mathrm{y}=-0.005 \mathrm{x}+27.54$ \\
FRAP-ORAC & 0,82 & $\mathrm{y}=1.463 \mathrm{x}+74.0$ & 0.17 & \\
FRAP- CBA & 0.27 & $\mathrm{y}=-2.794 \mathrm{x}+322.7$ & 0.10 & $\mathrm{y}=-0.462 \mathrm{x}+178$ \\
ORAC- CBA & 0.60 & $\mathrm{y}=-10.76 \mathrm{x}+814.5$ & 0.84 & $\mathrm{y}=9.647 \mathrm{x}+58.74$ \\
Lut-7-Glu-FRAP & - & - & 0.47 & $\mathrm{y}=0.143 \mathrm{x}-0.2$ \\
Lut-7-Glu-ORAC & - & - & 0.60 & $\mathrm{y}=-0.345 \mathrm{x}+380.6$ \\
Lut-7-Glu- CBA & - & - & 0.87 & $\mathrm{y}=-0.043+34.79$ \\
Rutin-FRAP & 0.89 & $\mathrm{y}=0115 \mathrm{x}+131.9$ & 0.75 & $\mathrm{y}=0.128 \mathrm{x}+145.8$ \\
Rutin-ORAC & 0.54 & $\mathrm{y}=0.124 \mathrm{x}+297.5$ & 0.14 & $\mathrm{y}=-0.064 \mathrm{x}+325.7$ \\
Rutin- CBA & 0.12 & $\mathrm{y}=0.001 \mathrm{x}+39.12$ & 0.46 & $\mathrm{y}=-0.017 \mathrm{x}+29.40$ \\
Cy-3-Glu-FRAP & 0.96 & $\mathrm{y}=0.075 \mathrm{x}+159.1$ & 0.75 & $\mathrm{y}=0.128 \mathrm{x}+145.8$ \\
Cy-3-Glu-ORAC & 0.74 & $\mathrm{Y}=0.102 \mathrm{x}+312.4$ & 0.14 & $\mathrm{y}=-0.064 \mathrm{x}+325.7$ \\
Cy-3-Glu- CBA & 0.03 & $\mathrm{y}=0 \mathrm{x}+40.37$ & 0.46 & $\mathrm{y}=-0.017 \mathrm{x}+29.40$ \\
Cy-3-rutin-FRAP & 0.97 & $\mathrm{y}=0.046 \mathrm{x}+153.1$ & 0.61 & $\mathrm{y}=2.821 \mathrm{x}+150.1$ \\
Cy-3-rutin-ORAC & 0.78 & $\mathrm{y}=0.065 \mathrm{x}+300.7$ & 0.83 & $\mathrm{y}=-10.12 \mathrm{x}+472.7$ \\
Cy-3-rutin- CBA & 0.08 & & 0.75 & $\mathrm{y}=-0.984 \mathrm{x}+40.74$ \\
\hline
\end{tabular}

*Significant at $P \leq 0.05$.

Lut-7-gluc: luteoline-7-glucoside, Cy-3-gluc: Cyanidin-3-glucoside, Cy-3-rut: Cyanidin-3-rutinoside. 
ORAC in fresh olives ( $\mathrm{r}=0.82)$, but only a slight one was noted between the same assays in salted olives $(\mathrm{r}=0.17)$. This can be explained by the different antioxidant compositions, since salting had an impact on these compounds and not all antioxidants can act as hydrogen donors or as iron reducers. In addition, the possibility of a synergistic effect among the antioxidants of fresh olives may explain the high antioxidant activity coefficient of the olive extracts.

Among the antioxidant activity methods used, the FRAP assay was highly correlated with each flavonoid identified in fresh or salted olives, although $\beta$-carotene bleaching activity appears to be more correlated with luteoline-7-glucoside contents.

\section{CONCLUSION}

In the present study, we evaluated the effect of dry salting on the flavonoid profile and antioxidant activity of five Algerian olive cultivars. We demonstrated that the changes in these compounds and antioxidant capacity occurring after processing depend on the cultivar. The HPLC analysis of the extracts revealed the presence of four flavonoids: rutin, luteolin-7-glucoside, cyanidin-3-glucoside and cyanidin-3-rutinoside. Among the antioxidant activity assays used, a good correlation was noted between FRAP and total flavonoid contents, indicating that these compounds could be among the main constituents responsible for the reducing ability of olives. An inclusive evaluation of all possible antioxidant activities would require a combination of several methods since varying results are obtained. This study supplied new information on the antioxidant capacity of olives for consumers and nutritionists, especially with this kind of process. In this work, we focused on hydrophilic extracts, although lipophilic components would be necessary to complete the data presented here.

\section{ACKNOWLEDGEMENTS}

Thanks are due to Ifri-Olive, $\mathrm{Mr}$ Ait Kheddache $\mathrm{S}$. and all those who have harvested the olive samples used in this study, and to the Algerian Ministry of Higher Education and scientific Research who funded this work. This work was also supported by project AGL 2009-07512 from the Spanish Government and The European Union (European Regional Development Funds).

\section{REFERENCES}

Alu'datt MH, RababahT, Ereifej K, Alli I. 2013. Distribution, antioxidant and characterisation of phenolic compounds in soybeans, flaxseed and olives. Food Chem. 139, 93-99. http://dx.doi.org/10.1016/j.foodchem.2012.12.061.

Benzie I, Strain J. 1996. The ferric reducing ability of plasma (FRAP) as a measure of "antioxidant power": The FRAP Assay. Anal Biochem. 239, 70-76. http://dx.doi.org/10.1006/ abio.1996.0292.
Bianchi G. 2003. Lipids and phenols in table olives. Eur. J. Lipid Sci. Technol. 105, 229-242. http://dx.doi.org/10.1002/ejlt. 200390046.

Brahmi F, Mechri B,DhibiM, Hammami M. 2013. Variations in phenolic compounds and antiradical scavenging activity of Oleaeuropaealeaves and fruits extracts collected in two different seasons. Ind. Crops Prod. 49, 256-264. http://dx.doi. org/10.1016/j.indcrop.2013.04.042.

Brenes M, Rejano L, Garcia P, Sanchez AH, Garrido A. 1995. Biochemical changes in phenolic compounds during spanish-style green olive processing. J. Agric. Food Chem. 43, 2702-2706. http://dx.doi.org/10.1021/jf00058a028.

Damak N, Bouaziz M, Ayadi M, Sayadi S, Damak M. 2008. Effect of the maturation process on the phenolic fractions, fatty acids, and antioxidant activity of the chétoui olive fruit cultivar. J. Agric. Food Chem. 56, 1560-1566. http:// dx.doi.org/10.1021/jf072273k.

Dhanya R, Arun KB,Syama HP, Nisha P, Sundaresan A, Santhosh Kumar TR, Jayamurthy P. 2014. Rutin and quercetin enhance glucose uptake in L6 myotubes under oxidative stress induced by tertiary butyl hydrogen peroxide. Food Chem. 158, 546-554. http://dx.doi.org/10.1016/j. foodchem.2014.02.151

Dimitrios B. 2006. Sources of natural phenolics antioxidants.Trends Food Sci. Tech. 17, 505-512. http://dx.doi. org/10.1016/j.tifs.2006.04.004.

Du G, Li M, Ma F, Liang D. 2009. Antioxidant capacity and the relationship with polyphenol and Vitamin C in Actinidia fruits. Food Chem., 113, 557-562. http://dx.doi.org/ 10.1016/j.foodchem.2008.08.025.

Erlund I. 2004. Review of the flavonoids quercetin, hesperetin, and naringenin. Dietary sources, bioactivities, bioavailability, and epidemiology. Nutr. Res. 24, 851-874. http:// dx.doi.org/10.1016/j.nutres.2004.07.005.

Garrido-Fernández A, Fernández-Díez MJ, Adams MR. 1997. Table olives: Production and processing. In Olives and table olives (pp. 10-21). London, UK: Chapman and Hall.

ITAFV. 2011. Institut Technique de l'Arboriculture Fruitière et de la Vigne. Statistiques 2011 des olives de table. Département Etude Direction Générale (Alger).

Kim DO, Chun OK, Kim YJ, Moon HY, Lee CY. 2003. Quantification of polyphenolics and their antioxidant capacity in fresh plums. J. Agric. Food Chem. 51, 6509-6515. http://dx.doi.org/10.1021/jf0343074.

McDonald S, Prenzler PD, Antolovich M, Robards K. 2001. Phenolic content and antioxidant activity of olive extracts. Food Chem. 73, 73-84. http://dx.doi.org/10.1016/ S0308-8146(00)00288-0.

Morales-Soto A, García-Salas P, Rodríguez-Pérez C, JiménezSánchez C, Cádiz-Gurrea M, Segura-Carretero A, Fernández-Gutiérrez A. 2014. Antioxidant capacity of 44 cultivars of fruits and vegetables grown in Andalusia (Spain). Food Res. Int . 58, 35-46. http://dx.doi.org/10.1016/ j. foodres.2014.01. 050

Morello JR, VuorelaS, Romero MP, Motilva MJ, Heinonen M. 2005. Antioxidant activity of olive pulp and olive oil phenolic compounds of the Arbequina cultivar. J. Agric. Food Chem. 53, 2002-2008. http://dx.doi.org/10.1021/jf048386a.

Ou B, Huang D, Hampsch-Woodill M, Flanagan JA, Deemer EK. 2002. Analysis of antioxidant activities of common vegetables employingoxygen radical absorbancecapacity(ORAC) andferricreducing antioxidant power (FRAP) assays: a comparativestudy. J. Agric. Food Chem. 50, 3122-3128. http://dx.doi.org/10.1021/jf0116606.

Panagou, E. Z. 2006. Greek dry-salted olives: Monitoring the dry-salting process and subsequent physico-chemical and microbiological profile during storage under different packing conditions at 4 and $20^{\circ}$ C. Food Sci. Technol. 39, 322-329. http://dx.doi.org/10.1016/j.lwt.2005.02.017.

Piscopo A, De Bruno A, Zappia A, Poiana M. 2014. Antioxidant activity of dried green olives (Caroleacv.). Food Sci Technol. 58, 49-54. http://dx.doi.org/10.1016/j.lwt.2014.03.013.

Prior RL, Hoang H, Gu L, Wu X, Bacchiocca M., Howard L, Hampsch-Woodill M, Huang D, Ou B, Jacob R. 2003. Assays for hydrophilic and lipophilic antioxidant capacity (oxygen radical absorbance capacity (ORACFL)) of plasma 
and other biological and food samples. J. Agric. Food Chem. 51, 3273-3279. http://dx.doi.org/10.1021/jf0262256.

Prior R, WuX, Schaich K. 2005. Standardized methods for the determination of antioxidant capacity and phenolics in foods and dietary supplements. J. Agric. Food Chem. 53, 4290-4302. http://dx.doi.org/10.1021/jf0502698.

Rice-Evans CA, Packer L. 2003. Flavonoids in Health and Disease. In Pietta, P. \& Gardana, C. Flavonoids in herbs (pp. 43-50). CRC Press.

Romero C, García P, Brenes M, García A, Garrido A. 2002a. Phenolic compounds in natural black Spanish olive varieties. Eur. Food Res. Technol. 215, 489-496. http://dx.doi. org/10.1007/s00217-002-0619-6.

Romero C, Brenes M, García P, Garrido A. 2002b. Hydroxytyrosol 4- $\beta$-D-glucoside, an important phenolic compound in olive fruits and derived products. J. Agric. Food Chem. 50, 3835-3839. http://dx.doi.org/10.1021/ jf011485t.

Rufino MM, Alves RE, Brito ES, Pérez-Jiménez J, SauraCalixto F, Mancini-Filho J. 2010. Bioactive compounds and antioxidant capacities of 18 non-traditional tropical fruits from Brazil. Food Chem. 121, 996-1002. http:// dx.doi.org/10.1016/j.foodchem.2010.01.037.

Sánchez AH, Romero C, Ramírez E, Brenes M. 2013. Storage of mechanically harvested Manzanilla olives under controlled atmospheres. Postharvest Biol.Tech. 81, 60-65. http:// dx.doi.org/10.1016/j.postharvbio.2013.02.015.
Savarese M, De Marco E, Sacchi R. 2007. Characterization of phenolic extracts from olives (Olea europaea $c v$. Pisciottana) by electrospray ionization mass spectrometry Food Chem. 105, 761-770. http://dx.doi.org/10.1016/j. foodchem.2007.01.037.

Soufi O, Romero C, Louaileche H.2014. Ortho-diphenol profile and antioxidant activity of Algerian black olive cultivars: Effect of dry salting process. Food Chem. 157, 504-510. http://dx.doi.org/10.1016/j.foodchem.2014.02.075.

Sousa A, Malheiro R, Casal S, Bento A, Pereira JA.2014. Antioxidant activity and phenolic composition of $\mathrm{Cv}$. Cobrançosa olives affected through the maturation process. J. Funct. Foods. 11, 20-29. http://dx.doi.org/10.1016/j. jff.2014.08.024.

Tomás-Barberán F.A, Gil M.I. 2008. Improving the HealthPromoting Properties of Fruit and Vegetable Products. Woodhead Publishing Series in Food Science, Technology and Nutrition, CRC Press LLC. pp. 458-461.

Velioglu YS, Mazza G, Gao L, Omah BD. 1998. Antioxidant activity and total phenolics in selected fruits, vegetables, and grain products. J. Agric. Food Chem. 46, 4113-4117. http://dx.doi.org/10.1021/jf9801973.

Ziogas V, Tanou G, Molassiotis A, Diamantidis G, Vasilakakis M. 2010. Antioxidant and free radicalscavenging activities of phenolic extracts of olive fruits. Food Chem. 120, 1097-1103. http://dx.doi.org/10.1016/j. foodchem.2009.11.058 